\title{
(Des)caminhos da migração pendular na metrópole do Rio de Janeiro - uma perspectiva a partir dos eixos de transporte
}

\author{
Luciano Ximenes Aragão*
}

Pôr em perspectiva a migração pendular significa colocar em destaque os termos da urbanização recente. Essa perspectiva permite ainda a identificação do modo pelo qual se estabelecem as contradições envolvidas no crescimento da metrópole, assim como levanta os aspectos da estruturação do espaço urbano, em especial quando se destaca a relação entre o centro e a periferia. Revela-se, desta maneira, a dinâmica das articulações entre distintos territórios. Este artigo tem por origem trabalhos de campo realizados nos terminais de trem e nos rodoviários, apreendendo o momento em que se dá a própria mobilidade. Seu enfoque é a observação de alguns aspectos sobre os principais eixos viários que ligam os centros de emprego aos bairros periféricos, considerados "dormitórios". Enfatizase a dialética existente entre a mobilidade e o seu outro - a contra-mobilidade - a partir de um caso específico. Assim os eixos privilegiados foram os ferroviários - as linhas de trem, com ênfase sobre o ramal Santa Cruz - e os rodoviários - privilegiando o que liga a Barra da Tijuca aos bairros de Bangu, Santa Cruz e Campo Grande, portanto os principais eixos de transporte que ligam os centros de emprego aos bairros dos subúrbios do núcleo intrametropolitano. Pois,

* Luciano Ximenes Aragão é doutorando em Geografia Humana pela FFLCH/USP - Bolsista CNPq. 
[A] vida urbana é toda colocada sob o signo da mobilidade (...). E os fluxos migratórios, os deslocamentos espaciais e mobilidades habitacionais, os percursos ocupacionais e suas inflexões no tempo e no espaço, traduzem na escala dos destinos individuais e coletivos a dinâmica das transformações urbanas. Essa pode ser uma via fecunda para uma descrição das mudanças recentes (TELLES, 2006, p.62-63).

Desse modo, aponta-se o pressuposto de que os trabalhadores urbanos submetidos à migração pendular, não constituem massa amorfa, no sentido de que grande quantidade de pessoas realiza esse movimento de casa para o trabalho e deste para seus espaços de descanso e lazer, que se desloca entre os espaços de uma grande cidade como a metrópole do Rio de Janeiro, não se traduz em algo mecânico. Nessa mobilidade pendular conjugam-se estratégias dentro do próprio movimento que se realiza. Não se trata de uma atividade banal - o ir e vir para o trabalho - e sim de trajetórias urbanas que recuperam a dimensão simbólica em que o processo se desenvolve. Trata-se de enfocar a esfera da reprodução imbricada na da produção. Articula-se de variadas maneiras a esfera da produção - do trabalho - com a esfera da reprodução - do não-trabalho.

\section{A expansão urbana e o surgimento da periferia: A macrossegregação na cidade do Rio de Janeiro}

Até praticamente o final do século XIX, a população da cidade do Rio de Janeiro estava concentrada entre os Morros do Castelo, São Bento, Santo Antonio e da Conceição. Era quase ausente a separação entre os locais de residência da classe trabalhadora e das classes mais abastadas. Para Maurício de Abreu (1987) a separação entre os usos e classes se estabeleceria a partir do início da década de 1870, com a introdução dos bondes puxados a burro e com a inauguração dos primeiros ramais ferroviários, os quais marcarão o início de expansão física da cidade. Os bairros localizados próximos ao Centro e à Zona Sul se destinaram à ocupação daqueles grupos sociais mais aquinhoados, enquanto em direção à periferia, se dirigiam os grupos populares.

As contradições, então, eram visíveis no espaço urbano. Viver no centro era condição de sobrevivência, pois a procura por trabalho era diária e se daria nos locais onde havia maior concentração da população. A precariedade dos transportes - atrasos, superlotação e o alto custo - contribuiu para a permanência de parte da população mais empobrecida nas áreas centrais da cidade. Todavia, impunha-se a necessidade de modernizar sua área central, já que a metrópole deveria estar à altura de competir com as rivais do Cone Sul (Montevidéu e Buenos Aires), através da abertura de vias públicas, embelezamento, arrasamento de morros e dos quarteirões constituídos por cortiços, local de residência de parte dos trabalhadores (ABREU, 1987). 
Estavam dadas as condições para a segregação espacial induzida, ora pelo capital, ora pelo Estado, ora pela ação conjunta de ambos, que perdurou durante grande parte do século XX, marcando a estrutura urbana da metrópole carioca: os bairros centrais e suas proximidades, dotados de infraestrutura urbana, tornaram-se locais de residência das classes de média e alta renda; as periferias com infraestrutura precária quanto mais distante do núcleo, local de residência de grande parte da população trabalhadora.

Os anos que se seguiram à década de 1920 se caracterizaram pelo higienismo com respeito às políticas de intervenção sobre os espaços da cidade e respectivos planos urbanísticos. Para o caso do Rio de Janeiro tiveram como pano de fundo o plano do arquiteto francês Alfred Agache. Foram priorizadas as áreas centrais do espaço urbano. Todavia, as ações (ou omissões) do Estado sempre foram pontuais. No início dos anos 1930 as migrações internas excedem as migrações internacionais e o Rio de Janeiro recebe um contingente cada vez maior de nordestinos e mineiros. $\mathrm{O}$ aumento acelerado da população provoca dificuldades do pretenso controle social sobre o uso do solo urbano via normatização que inibia novas ocupações nas áreas da cidade pela população de baixa renda. Para Abreu (op. cit.), a tentativa de superação das contradições pré-existentes promoveu a emergência de novas contradições.

Os anos sessenta do século XX assumem contornos mais dramáticos para a população trabalhadora que insistia em viver nas áreas centrais do espaço metropolitano carioca. É o auge do processo de remoções de áreas faveladas, tendo em vista alavancar a valorização do solo e/ou "limpar" os espaços de maior valor econômico e simbólico da cidade para fins de melhorias de seu sistema viário. O seu resultado foi a remoção de uma série de favelas, condenando-se seus moradores a uma mobilidade compulsória. Muitos deles tiveram de se mudar para áreas distantes do núcleo metropolitano, indo viver nos monótonos, precários, distantes e feios conjuntos habitacionais. Radicou-se uma política habitacional que resultou em distorções (VALLADARES, 1978).

A década de setenta do século passado marca processos qualitativamente bastante diferenciados em relação aos períodos anteriores. A expansão física ultrapassa os bairros da Zona Sul, considerada saturada; o eixo de urbanização atinge a Barra da Tijuca e parte da Baixada de Jacarepaguá, orientado pelo plano urbanístico do arquiteto Lúcio Costa. Outro eixo de expansão compreendeu a Baixada Fluminense, densificando a mobilidade intrametropolitana. Enquanto o primeiro eixo teve um aspecto ordenado, posto que fora contemplado com a intervenção do Estado através de um plano urbanístico e de dotação de infraestrutura, em especial através da construção de viadutos sobrepostos e de abertura de vias expressas, o segundo apresentou um caráter desordenado, com ausência de infraestrutura, sem financiamento das habitações, na medida em que os próprios trabalhadores realizavam a construção de suas moradias e da infraestrutura através de mutirões, nos finais de semana e/ou nos momentos de folga (LEITÃO, 1999). 
Contudo, outro aspecto deve ser mencionado com relação à estrutura urbana da metrópole carioca: o surgimento de vários subcentros nas áreas periféricas, causados em grande parte, pela densificação populacional, mas também por uma relativa desconcentração das atividades econômicas. Para os bairros dos subúrbios e municípios da periferia convergem crescentemente fluxos de população seja do interior do estado, seja das migrações intrametropolitanas e ainda das migrações inter-regionais, revelando-se, desse modo, a complexidade que cerca os espaços periféricos, cuja dinâmica na sua apreensão nem sempre é captada adequadamente pelos censos demográficos.

Vale lembrar, contudo, as temporalidades que permeiam essa convergência: até os anos sessenta do século XX, a Região Metropolitana do Rio de Janeiro acompanhava a teia do próprio processo de metropolização brasileiro, marcado por forte atração populacional, alimentado pelas migrações inter-regionais; na década seguinte o saldo migratório é quase nulo e a partir dos anos oitenta, acentua-se a migração interestadual com tendência de concentração da população na periferia metropolitana, conforme aponta Oliveira (2005).

Desse modo, acentua-se o caráter concentrador do núcleo metropolitano e em paralelo, o significado do multifacetado deslocamento populacional, na medida em que outras implicações Ihe são subjacentes, sendo seus exemplos a mobilidade residencial e as migrações pendulares inscritas, em grande medida na trajetória migrante. As trajetórias individuais e/ou dos grupos sociais, uma vez analisadas suas biografias, podem absorver uma sequência iniciada pela migração de longa distância, passando pela mobilidade residencial e sua culminância pode ser estabelecida na migração pendular.

Os dados apontados por Oliveira (op. cit.) também sugerem que uma vez estabilizadas as migrações inter-regionais em direção ao Rio de Janeiro, supõe a confirmação de sua substituição (ou sobreposição) pela intensificação das migrações intraestaduais tanto dos municípios do interior, quanto do núcleo metropolitano em favor da sua periferia. Em suma,

O município-núcleo da região continuou sendo o de maior expulsão, 80 mil migrantes, algo próximo a $62 \%$ do total, seguido por Niterói, de onde partiram 15 mil pessoas. Com isso, a migração líquida do núcleo, nessa modalidade de trocas populacionais, tornou-se ainda mais negativa, ao passo que em todos os demais municípios o saldo migratório foi positivo, seguindo a tendência da região (OLIVEIRA, 2005, p. 355).

Na região metropolitana do Rio de Janeiro, entretanto, apesar dos efeitos da desconcentração se fazerem sentir, a área central permanece como importante centro de emprego, lazer e serviços. Ao mesmo tempo, os conflitos e tensões que caracterizam a relação entre os meios de transportes e os locais de residência, 
nos quais estão os deslocamentos diários da população de casa para o trabalho e vice-versa, permanecem. É necessário destacar no contexto destas permanências, as continuidades no que diz respeito às precariedades vividas pela população nos últimos anos. Não houve grandes mudanças em termos de melhoria das condições de vida, sobretudo no que se refere aos deslocamentos diários. Residir na periferia da cidade do Rio de Janeiro, assim como de qualquer outra grande metrópole brasileira é arcar com a precariedade dos meios de transporte, incluindo-se o tempo de deslocamento, o alto custo, a superlotação e os atrasos periódicos.

Diariamente milhares de trabalhadores se deslocam nos principais eixos viários que ligam os municípios da periferia ao núcleo metropolitano carioca, assim como seus bairros periféricos em direção aos centros de emprego, lazer e serviços. A forte concentração dos equipamentos urbanos e de ocupações caracteriza ainda centralidade de atividades econômicas e põem em evidência a mobilidade metropolitana, a despeito dos processos de desconcentração em curso.

Uma grande quantidade diária de deslocamentos de pessoas se dá através de seus principais eixos viários: o rodoviário, o ferroviário (metrô e trens) e ainda o hidroviário que liga a área central ao município de Niterói ${ }^{1}$.

Outros terminais, contudo, são localizados fora das áreas centrais, como por exemplo, o Terminal Alvorada, localizado na Barra da Tijuca, predominando as ligações com outros bairros periféricos da Zona Oeste e com municípios da Baixada Fluminense (Seropédica, Guapimirim e Mangaratiba).

É significativo acrescentar os terminais situados nas áreas periféricas, pois estes trazem à luz as modulações urbanas em que a mobilidade se apoia, ou seja, os trabalhadores no seu processo de deslocamento nas áreas metropolitanas atravessam vários espaços metropolitanos. Atingir um desses terminais pode se configurar em apenas uma das etapas de seus deslocamentos diários.

Os deslocamentos diários se complexificam na medida em que são múltiplos os seus vetores e estes se apresentam relacionados à própria dinâmica metropolitana, evidenciando suas transformações. Conforme apontado pela socióloga Vera Telles:

Se a cidade é campo de práticas para lembrar aqui novamente, a sugestão de Roncayolo, então as evidências empíricas que indicadores e cartografias nos entregam podem e devem ser entendidos como pontos de cristalização das práticas e processos, como pontos de condensação de tempos sociais e temporalidades urbanas, experiência social e sedimentada e história incorporada (Bourdieu) que será preciso reativar para o deciframento dos sentidos e direções das evoluções recentes que atravessam as realidades urbanas (TELLES, 2006). 


\section{(Des) caminhos e modulações da metrópole à luz da mobilidade espacial da população}

As observações de campo (iniciadas em 2007) objetivaram identificar não apenas meros flagrantes dos deslocamentos diários, privilegiando dois eixos de transporte na metrópole do Rio de Janeiro, mas captar seus sentidos imbricados no cotidiano. O primeiro eixo observado é o que faz a ligação entre a Barra da Tijuca - bairro de classe média alta - localizada na Zona Oeste do Rio de Janeiro e outros bairros e municípios periféricos. Inserido em parte da expansão urbana da cidade do Rio de Janeiro, a partir da década de 1970, rapidamente transformou-se num dos principais centros de emprego, (alguns) serviços e lazer (quando este não é seletivo) para um contingente considerável da população trabalhadora que reside nos bairros do subúrbio da cidade do Rio de Janeiro (Santa Cruz, Bangu, Campo Grande) e de alguns municípios limítrofes, localizados na Baixada Fluminense (Itaguaí, Seropédica, Nova Iguaçu, etc.). Um segundo, priorizou o ramal Santa Cruz, através do transporte ferroviário.

Pretensiosamente, as observações de campo se destinavam a apreender certo ritmo, cujo estudo cobre uma zona imensa, tentando isolar um deles para compreender o que vem de sua natureza, e, embora seja tarefa difícil é possível que tenha um alcance ético, isto é, prático: quando o saber do vivido [pode] modificá-lo sem se dar conta disto (LEFEBVRE, 1992, p. 30). O ritmo consiste num módulo da vida impresso num momento que se considerou aqui providencial, o próprio deslocamento, sob a pressuposição de escapar da sua dimensão mecânica. Assim, a rythmanalyse, propõe

[e]scutar o mundo, mas não somente as palavras e as informações, as confidências de um parceiro, de um cliente e sobretudo o que se nomeia desdenhosamente de ruídos, que se tem dito sem significação, e os rumores plenos de significação e enfim se escuta os silêncios (LEFEBVRE,1992, p. 31).

Destacar e escutar os ritmos demanda atenção, certo tempo, continua o filósofo Henri Lefebvre (op. cit.). Assim, as observações sobre o cotidiano no transporte coletivo propostas aqui objetivam apreender o que nos mostram os silêncios e os gestos.

Apresentam-se as situações vividas pelos grupos de trabalhadores que usualmente se encontram no eixo que liga a Barra da Tijuca aos bairros periféricos. Os ônibus que operam nesse trajeto, via Avenida das Américas, nos horário de 
pico, por volta das seis da tarde e das sete da manhã, estão sempre superlotados, portanto, as dificuldades a que os trabalhadores são submetidos são enormes: como estão sempre com a lotação máxima, alguns passageiros têm dificuldades de tomá-los; são frequentes os congestionamentos e não poucas vezes, os ônibus enguiçam, conforme relato de uma de suas passageiras:

Os pés doem. Chega uma hora que dá uma ardência
danada. Os braços ficam todo tempo levantado e
esticado assim e de vez em quando sinto dores também.
O calor terrível é massacrante. Teve uma vez que teve
uma batida e eu cheguei em casa, em Bangu, que não
tava agüentando ficar em pé. Vim desde a barra de pé.
(Relato de Bete, uma das passageiras do ônibus).

Este comentário foi mencionado a outra passageira e a mim com quem conversava. O ônibus, apesar de já muito cheio continuava tomando passageiros, cujas reações de indignação se sucediam. Alguns diziam "não cabe mais ninguém", às vezes, isto era dito sorrindo. As irritações também permaneciam. Os que entravam por último pedindo licença para se acomodar no interior do ônibus provocavam como reação, ora irritação por parte de alguns passageiros, ora risos, por parte de outros.

A parte da frente do coletivo é ocupada predominantemente por mulheres. Segundo o que Bete diz, no seu jeito muito descontraído de falar, a maioria tem como ocupação principal o serviço de diarista. Cita o exemplo de várias colegas, amigas e vizinhas. "Uma diz à outra onde tem precisão deste tipo de trabalho".

Na parte traseira do ônibus, se concentram os homens. Ao som de um cavaquinho e de um pandeiro, inicia-se a cantoria do pagode. Uma amiga de Bete diz que "todos os dias é assim". O mesmo grupo, formado por homens e umas poucas mulheres toma aquele ônibus, sempre no mesmo horário e "esse é o divertimento deles, ali atrás".

Enquanto o período do final da tarde apresenta a possibilidade de se notar que entre a maior parte desses migrantes pendulares predominam empregados domésticos, prestadores de serviços ligados à construção civil (pedreiros, marceneiros, gazistas, eletricistas, bombeiros hidráulicos, pintores), no período noturno, conforme informações de um cobrador de ônibus, a maioria dos passageiros é do setor de restaurantes e dos shoppings. Observou-se que, mesmo à noite, permanecem as "reuniões" desses grupos no interior dos coletivos. O lúdico, novamente é, neste caso, recuperado, com conversas sobre situações embaraçosas vividas durante o período de trabalho; é o momento em que a "fofoca" revela a sociabilidade, experimentada por distintos grupos sociais. 
Se, por um lado, o urbanismo moderno privilegiou o automóvel e a rua se tornou o lugar de passagem, o lugar da mobilidade, por outro lado esses registros nos mostram, em alguns momentos, como o coletivo passa a se tornar o lugar do encontro através de determinados ritmos (da vida) os quais incluem o uso do espaço e do tempo dentro de uma estratégia de reprodução.

O tempo gasto nas viagens é utilizado para os lazeres, onde ocorrem os encontros, mas também para a realização e ativação de certas redes sociais. Desse modo, os deslocamentos escapam de sua dimensão, por assim dizer, mecânica, porque incorporam a espontaneidade que era vivida na rua.

As situações aí presenciadas sugerem que o corpo, em condições de acumulação capitalista, torna-se a "medida de todas as coisas". O espaço que resta para esses trabalhadores é residual, posto que os tamanhos dos bancos e das cadeiras e a altura do coletivo estão na exata medida do corpo.

O outro eixo que faz a ligação dos lugares de residência aos centros de emprego, serviços e lazer, como já apontado, são os ramais do trem. A movimentação de pessoas impressiona, pois a estação "Central do Brasil" dá acesso ao metrô e ao terminal Américo Fontenele. Portanto, aí se destaca um importante entroncamento dos sistemas de transporte da região metropolitana. Na metrópole carioca, a observação enfatizou o ramal Santa Cruz, bairro periférico da cidade que se limita com o município de Itaguaí.

Os sons na hora do embarque são os mais diversos. A correria e os passos apressados para não perder os trens marcam os ritmos que tomam de assalto a estação terminal Central do Brasil.

As linhas ferroviárias foram privatizadas em 1998 e um constrangimento à mobilidade é a sua consequência mais marcante. Com a reforma das estações e com um maior rigor na vigilância, muitas pessoas, que antes se valiam de certas estratégias para viajar gratuitamente, já não o conseguem, informa um dos condutores. Do mesmo modo, antes das privatizações os passageiros realizavam mudanças e/ou transporte de objetos entre uma estação e outra, acrescenta o referido condutor.

À primeira vista, a estação "Central do Brasil" se nos apresenta como um lugar de passagem. Atravessados os torniquetes que dão acesso às plataformas de embarque, uma observação mais atenta revela certo compasso que põe em relevo as modulações urbanas (TELLES, op. cit.). Os passageiros se posicionam nos lugares das enormes plataformas, onde possam encontrar conhecidos e amigos que costumam viajar naqueles mesmos horários. No primeiro vagão é onde se desenvolve o encontro de um grupo que rotineiramente aí joga o carteado. Apesar do trem lotado, mesmo de pé, jogam o baralho. Um entre eles é escolhido para segurar as cartas, substituindo a mesa. As brincadeiras entre eles e o revezamento que se estabelece entre os que perderam e que têm de sair para dar vez aos outros 
que estavam de fora do jogo denuncia que os encontros são diários. Mesmo os que não jogam, observam atentamente o jogo e se envolvem, atribuindo apelidos de acordo com as características físicas de cada um deles.

Os vagões seguintes são destinados exclusivamente às mulheres, definidos por lei estadual, nem sempre cumprida, apesar do grande número de seguranças privados existentes na plataforma. Estes vagões são sucedidos por aqueles onde se encontram os evangélicos. As pregações são alternadas pelos cânticos da "harpa cristã" e por orações. É com o corpo e suas manifestações (cantar e pregar em voz alta) que aqui aparecem como supostas estratégias para afastar aqueles que não são simpatizantes. Assim, demarca-se um território, pois aquele que não deseja ouvir as pregações busca outro vagão, como foi observado. Vale notar que esses grupos de evangélicos encontram-se corriqueiramente, pois foi percebido que se cumprimentavam e a seguir teciam alguns comentários de histórias, cujo início se dera nos dias anteriores. Portanto, havia uma sequência de acontecimentos em curso que revelava as relações sociais travadas por esse grupo. Vale acrescentar, contudo, que o interesse desses grupos não se destinava à evangelização, na medida em que não se notava a abordagem de passageiros desconhecidos; a preferência estava mesmo sobre o desenvolvimento de um culto. Todos permaneciam com uma mão nas barras situadas um pouco acima da cabeça e com a outra na bíblia ou hinário, respondendo as orações que então se desenvolviam.

O último vagão, segundo comentário de um dos passageiros, é o menos disputado. É rejeitado "devido à presença de malfeitores", sobretudo nos períodos noturnos, conforme a fala de um passageiro que olha pro horizonte, faz uma pausa e emenda: "dizem que tem até tráfico de drogas".

A privatização da rede ferroviária tenta impor certa ordem à suposta desordem existente anteriormente, momento em que o Estado era o detentor de seu controle. Há forte repressão sobre os vendedores ambulantes que vendem de tudo, desde produtos contrabandeados até os das grandes multinacionais, dificultando a definição de fronteiras entre o formal e o informal, o lícito e o ilícito. Doces, chocolates, amendoins, cervejas, refrigerantes, produtos para a queda de cabelo, micose, coceiras, ervas para combater a diabetes, entre (muitas!) outras variadas mercadorias.

A tensão entre o instituinte e o instituído é notória. Da estação da Central até a de Deodoro a repressão sobre ambulantes é mais intensa ${ }^{2}$. Os que são cadastrados e uniformizados têm permissão para circular entre as estações e dentro dos vagões, onde comercializam produtos de uma única marca. Os demais são advertidos com um apito dos seguranças da Supervia - empresa privada concessionária da rede ferroviária. 
As agressões físicas e o confisco dos produtos vendidos pelos ambulantes não são tão recorrentes. Acredita-se que isso pode causar a indignação dos demais passageiros e desencadear um confronto mais tenso. A solidariedade e a ética do trabalho assumem uma mistura não muito fácil de distinguir, fato observado na conversa entre os dois passageiros quando viram a investida de um dos seguranças privados da Supervia sobre um ambulante. "Não deixa as pessoas trabalharem. Isso pode acontecer com qualquer um que não tem nem como trabalhar. $O$ cara tá ali ganhando seu dinheiro honestamente e não tá roubando ninguém".

As estratégias dos ambulantes são as mais diversas. Dão preferência aos trens mais velhos e não aos mais modernos e que dispõem de ar condicionado. Estes são os mais vigiados, enquanto nos antigos há lugares em que é possível remover o tampo do banco e esconder as mercadorias que estavam sendo vendidas diante das investidas dos seguranças. Cada ambulante sabe qual é o vagão em que é possível realizar esta operação diante da presença "inesperada" de um dos seguranças. A rede de comunicação entre eles parece ser muito eficiente. Um diz ao outro onde há ameaça de presença de um destes repressores.

O comércio ambulante, a exemplo das ações dos evangélicos, também se apresenta territorializado, sugerindo o controle do espaço. Os ambulantes que atuam no ramal Japeri não podem atuar no ramal Santa Cruz.

As relações entre os passageiros e os ambulantes são amistosas. De certo modo, eles também recuperam o lado lúdico da viagem e alguns deles já são bem conhecidos pelos passageiros. A aproximação de um deles provoca comentários. Um exemplo é o de vendedor de "CDs piratas". A entonação de sua voz anunciando os filmes provoca risos. Outro exemplo é o vendedor de chocolates que começa a falar, muitas vezes repetindo uma longa frase, cujo final diz "vou ficar e só paro quando você comprar". A forma com a qual dialoga com os usuários também desencadeia momentos engraçados, que se repete com o vendedor de cocadas que diz: "Compre uma cocada e ganhe um oi: Oi!!!"

No repertório de histórias, os momentos de tensão assumem contornos dramáticos, cujo exemplo mais recente, ocorrido em 2008, foi desencadeado quando um raio atingiu um dos ramais da rede ferroviária. Os trens permaneceram parados durante muito tempo, por cerca de uma hora e meia, relata uma usuária. Esta disse ainda que a Estação Deodoro "parecia uma praça de guerra. Como os trens estavam demorando muito, as pessoas começaram a quebrar as placas da estação, chutaram vidros e socavam os trens que estavam parados. Tinha muita gente!".

Durante a greve parcial dos ferroviários, também em 2008, as tensões se repetiram. Os seguranças da Supervia agrediram os usuários com socos e chutes, empurrando-os para dentro dos vagões.

Outro exemplo de tensão recorrente vivido pelos trabalhadores pode ser observado nas constantes investidas do narcotráfico, particularmente no trecho 
entre as estações Bangu e Senador Camará. Os frequentes confrontos têm como resultado a paralisação temporária dos trens. E então é a imobilidade, ainda que temporária, que provoca a interrupção da viagem. O cansaço de um dia de trabalho é acrescido pela longa espera para que suas trajetórias prossigam.

Esse repertório de histórias reforça as contradições que subjazem no momento em que se observa a mobilidade pendular. Se por um lado o corpo aparece como estratégia de acumulação, por outro, as condições em que a mesma se dá promovem a violação, a desfiguração, a subjugação e a danificação do corpo que trabalha (HARVEY, 2004, p. 149).

\section{Nova Sepetiba - o constrangimento à mobilidade}

A mobilidade tem o seu outro - a imobilidade. A perspectiva sobre as trajetórias individuais tem várias implicações e a principal delas é colocar em primeiro plano as modulações do espaço urbano, através de determinadas biografias. E isto pode ser demonstrado, de forma particular, no caso dos moradores de Nova Sepetiba, onde o par dialético mobilidade/imobilidade assume contornos mais precisos.

Nova Sepetiba está localizada num dos limites da imensa Zona Oeste da cidade do Rio de Janeiro. Trata-se de um conjunto habitacional planejado no Governo Garotinho (que governou o Estado do Rio de Janeiro de 1999 a 2002) dentro de uma proposta populista/assistencialista de oferecer moradia "a um real".

São cerca de 4 mil casas, com previsão de habitação para 20 mil pessoas. Seus moradores, conforme entrevistas realizadas no local constituem-se de pessoas que viviam em situação de rua, desabrigados em função das obras do metrô e da Linha Amarela, além de um grupo originário do Caju (bairro situado junto ao início da Avenida Brasil, próximo dos armazéns do Cais do Porto) que foram vítimas de um incêndio. $O$ conjunto, previsto para ser o maior da América Latina, além de apresentar problemas relativos ao acesso aos serviços sociais básicos, é atingido também pela precariedade dos transportes. Repete-se a lógica da macrossegregação implícita na (i)lógica da política habitacional do Estado.

As trajetórias dos grupos são diversas, na medida em que são originários de distintas comunidades. Foram, desde a origem, condenados à mobilidade. Tornamse evidentes as modulações urbanas inscritas em distintas trajetórias. Conforme dito pelo líder comunitário Jonas, há muitos moradores que são nordestinos e, portanto, é possível identificar uma sucessão de mobilidades espaciais, vividas por um mesmo grupo. Iniciada com a migração inter-regional (de longa distância), o processo prossegue na migração pendular e culmina na imobilidade, como se verá a seguir. Entretanto, necessário se faz apontar, essa mobilidade assume contornos mais amplos e não se reduz apenas à mobilidade residencial - implicitamente se inclui a mobilidade social -e, se admite, se confunde com a imobilidade. 
De acordo ainda com o relato de Jonas, os moradores não podem fazer nenhuma alteração nas casas; é vedado o acréscimo ou transformação da parte da frente numa loja ou algo que possa garantir uma estratégia de sobrevivência, algo muito comum nas comunidades de baixa renda. Também não é permitido passar ou vender a casa, bem como quitá-la antes do prazo previsto no financiamento.

Esse quadro, em seu conjunto nos leva a interpretação de que os moradores de Nova Sepetiba, agora, estão fadados à imobilidade, em função dessas múltiplas interdições, a qual se adiciona à imobilidade espacial. Vivendo na periferia da cidade, Jonas novamente relata as dificuldades que os moradores têm de acessar uma ocupação. Viver em Nova Sepetiba tornou-se estigmatizante. Quando da procura por um emprego, na hora das negociações, se o morador do conjunto informa ser este seu local de residência, imediatamente ouve a recusa por parte do empregador.

Com relação aos transportes, o que é muito importante destacar, as dificuldades são ainda mais notáveis. Até o final de $2007^{3}$ havia apenas uma única linha de ônibus de acesso ao bairro e como esta é de ônibus especial (com ar condicionado) o preço da passagem era o dobro das convencionais. Como consequência, agravava-se mais ainda a dificuldade de encontrar emprego, pois os empregadores dão preferência a funcionários que possam apresentar menos custos na aquisição do vale transporte.

Conforme referido por Jonas e confirmado por outro residente entrevistado, muitos moradores trabalham no Centro e dormem debaixo das marquises de prédios porque não têm como retornar, dado o elevado preço da passagem.

O caso de Nova Sepetiba denuncia as contradições do espaço urbano. A situação por seus moradores se reflete na negação da cidadania em tempos de globalização em que se alarde, intensamente, a liberdade de circulação.

\section{A título de conclusão}

A pesquisa em torno da migração pendular, utilizando-se da rythmanalyse, digamos um método pouco convencional de pesquisa, destinou-se a apreender os interditos que envolvem o deslocamento espacial da população na região metropolitana no Rio de Janeiro. Colocar em perspectiva os gestos, os interditos, os silêncios constitui ponto de partida para destacar uma miríade de relações, as quais se destinaram a demonstrar como, na própria mobilidade, lança-se mão de estratégias que permitem juntar o lugar do trabalho com o do não-trabalho, o lugar da produção com o da reprodução, o espaço da festa (MARTINS, 1986).

Apesar das tensões e conflitos, é nestes espaços que se recupera o lúdico, o simbólico através da constituição e manutenção de relações sociais e então, supõe-se a superação dos lugares de passagem e da própria mobilidade cotidiana como algo mecânico. 
O contexto do desenvolvimento das migrações pendulares é o da mobilidade do trabalho (GAUDEMAR, 1976) dada pela capacidade do próprio capital constranger o movimento espacial do capital variável (aquele formado pela força de trabalho). Contudo, deve-se apontar para algumas especificidades em que a imobilidade, dialeticamente, subjaz aos deslocamentos diários da população.

Demonstra-se, desse modo, as permanências e continuidades sobre as migrações intrametropolitanas, cuja explicação é a própria manutenção das contradições presentes no espaço urbano, componentes dos termos da urbanização recente.

\section{Notas}

1 - Os terminais rodoviários e ferroviários inter e intramunicipais estão assim distribuídos: Terminal Menezes Cortes, junto ao CDB carioca, localizado numa parte do Centro conhecida como Castelo; terminal da Praça XV, predominando linhas de ônibus que ligam o Centro aos bairros do subúrbio e outras que fazem a ligação do Centro com municípios da borda ocidental da Baía de Guanabara (também na Baixada Fluminense); o Terminal Américo Fontenelle, cujas linhas de ônibus ligam o Centro aos municípios da orla oriental da Baía de Guanabara (Baixada Fluminense) e a poucos metros o terminal dos quatro grandes ramais ferroviários (Santa Cruz, Japeri, Belfod Roxo e Saracuna) e onde se localiza também a Estação Central do Metrô - linha 1 , que liga o Centro à Zona Sul e aos bairros do subúrbio. Em todos estes eixos acrescente-se o transporte alternativo de vans e kombis.

2 - A Estação Deodoro, localizada na Zona Norte é a última estação de transferência entre os trens paradores e os expressos. Trata-se de um entroncamento de três dos quatro ramais. Dois deles vão em direção aos municípios da Baixada Fluminense e o outro ao terminal Santa Cruz, localizado na periferia do município do Rio de Janeiro.

3 - Momento em que estavam sendo realizados os trabalhos de campo.

\section{Referências}

ABREU, Maurício de. Evolução urbana do Rio de Janeiro. Rio de Janeiro: Iplan-Rio/Jorge Zahar Editor, 1987.

GAUDEMAR, J. P. Mobilité du Travail et Acumulatión du Capital. Paris: Maspero, 1976.

HARVEY, D. Espaços de Esperança. São Paulo: Loyola, 2004.

LEFEBVRE, H. L. Éléments de Rythmanalyse. Introduction à la connaissance des rythmes. Paris: Editions Syppepse, 1992.

LEITÃO, G. A construção do Eldorado Urbano. Niterói: Eduff, 1999.

MARTINS, José de Souza. Não há terra para plantar nesse verão. Rio de Janeiro: Vozes, 1986.

OLIVEIRA, A. T. Fluxos migratórios na região metropolitana do Rio de Janeiro. In: PÓVOA-NETO, H.; FERREIRA, A. P. Cruzando Fronteiras Disciplinares. Um panorama dos estudos migratórios. Rio de Janeiro: NIEM/REVAN, 2005.

TELLES, V. da S. Debates: a cidade em questão. In: TELLES, V. da S.; CABANES, R. Nas tramas da cidade. Trajetórias urbanas e seus territórios. São Paulo: Associação Editorial Humanitas, 2006. 
VALLADADES, L. do Prado. Passa-se uma casa. Análise do programa de remoção de favelas no Rio de Jabneiro. Rio de Janeiro: Zahar Editores, 1978.

\title{
RESUMO
}

O presente texto procura demonstrar que o deslocamento diário da população não deve ser visto como algo mecânico. Na própria mobilidade, os trabalhadores urbanos lançam mão de estratégias que permitem a articulação de distintas modulações da vida e revelam que o corpo se apresenta como estratégia de acumulação. Não obstante, em alguns momentos particulares, o par dialético mobilidade/imobilidade assume contornos mais precisos.

Palavras-chave: mobilidade pendular; território; transportes urbanos.

\begin{abstract}
This text seeks to demonstrate that the daily movement of the population should not be seen as something mechanical. In the very mobility, urban workers develop strategies that articulates distinct modulations of life and reveals that the body is presented as a strategy of accumulation. Nevertheless, in some particular moments, the dialectic pair mobility/immobility becomes more precise.
\end{abstract}

Keywords: Commuting; territory; urban transport. 